\title{
A IDEIA DE JUSTIÇA NO CONCEITO PÓS- POSITIVISTA E SOB A ÓTICA DA TEORIA ESTRUTURANTE DO DIREITO DE FRIEDRICH MÜLLER
}

\begin{abstract}
Adonias Osias da Silva
Bacharel em Direito pela UNIBAN - Universidade Bandeirantes de São Paulo. Pós-graduado em Direito Tributário pela FIJ - Faculdades Integradas Jacarepaguá, Rio de Janeiro-RJ. Mestre em Direito pela EPD - Escola Paulista de Direito, São Paulo-SP. E-mail: adonias. silva@unifesp.br.
\end{abstract}

\section{Carla R. de Freitas Araújo}

Bacharel em Direito pela Faculdade de Direito de SBC, São Bernardo do Campo-SP. Pósgraduada em Direito do Trabalho pela UNIP-SP. Pós-graduada em Docência do Ensino Superior pela UNIP-SP. Mestranda em Direito pela EPD - Escola Paulista de Direito, São Paulo-SP. E-mail: carla_rfreitas@hotmail.com.

\begin{abstract}
Resumo: O presente ensaio tem por escopo uma análise crítica sobre a ideia de Direito que se tem na sociedade hodierna, bem como a visão pós-positivista de Friedrich Müller e a aplicabilidade da sua Teoria Estruturante do Direito (Strukturiende Rechtslehre Theorie) no Direito contemporâneo. Analisa-se o modelo positivista de aplicação do direito como é posto hoje, em comparação com o modelo estruturante proposto pelo autor alemão, e que se enquadra no denominado pós-positivismo. A par disso, é feita uma abordagem no que concerne ao modelo estático do positivismo clássico em contraponto ao modelo dinâmico de concretização do Direito proposto pela Teoria Estruturante do Direito. Por fim, com o presente texto, busca-se analisar as principais características da teoria alemã de aplicação do direito, mostrando que sua adoção no ordenamento pátrio viabilizaria, de um modo mais concreto, o ideal de justiça de há muito buscado na sociedade globalizada e pluralista em que vivemos e para isso não se pode olvidar o papel da hermenêutica como elemento-chave dessa mudança de paradigma.
\end{abstract}

Palavras-chave: Positivismo. Pós-positivismo. Direito contemporâneo. Teoria Estruturante do Direito. Hermenêutica.

Sumário: 1 Introdução - 20 Direito e suas dimensões evolutivas - $\mathbf{3}$ Direito sob o viés positivista - 4 A proposta de Friedrich Müller - $\mathbf{5}$ Atual momento jurídico - $\mathbf{6}$ Aplicação da Teoria Estruturante do Direito em nosso atual contexto jurídico - $\mathbf{7}$ Vigência e efetividade da norma jurídica - $\mathbf{8}$ A hermenêutica como ferramenta para interpretação da norma jurídica - 9 Conclusão - Referências

\section{Introdução}

A atividade intelectual científica requer do "ator" que irá adentrar na seara da pesquisa, ou seja, na esfera do SER, não apenas uma ótica imparcial e 
descomprometida com tudo o que já leu e aprendeu, como também um compromisso firme de aumentar seus conhecimentos sobre as particularidades da pesquisa e com isso fará necessariamente uma retrospectiva do antes, do hoje e o que se pretende fazer no futuro imediato acerca da busca da verdade do objeto a ser abordado. Eis o grande alvo que deve ser perseguido por todo aquele que se propõe às atividades em nível intelecto científico.

O escopo do presente texto é a compreensão do fenômeno jurídico, com toda sua complexidade e pluralidade de interpretações, mormente no que tange aos anseios da sociedade num clamor geral por justiça. Não há que se negar que a prestação jurisdicional pretendida já não encontra resposta à altura da demanda e isso resulta num Judiciário abarrotado de processos que já não cumpre seu papel como garantidor do direito efetivo. Posteriormente será feita uma análise entre vigência e efetividade da norma jurídica na busca de uma solução alternativa que venha preencher essa lacuna abismal, de há muito sentida e vivida pela sociedade moderna.

No mundo da ciência é senso comum afirmar que quem identificou corretamente o problema a ser auscultado já seria detentor de pelo menos $50 \%$ (cinquenta por cento) da busca da verdade. Entendida aqui verdade não como algo absoluto e intangivel, porém, verdade no sentido de se chegar à conclusão do que se busca alcançar, uma vez que a identificação errada do problema levaria fatalmente ao fracasso, na tentativa de se tentar encontrar todas as possiveis variáveis de solução do problema ou do fenômeno estudado.

Nessa linha de raciocínio, busca-se a análise da verdade do fenômeno jurídico com toda sua multiplicidade e complexidade de formas, na tentativa de se encontrar um meio viável à prática da justiça, deixando-se transparente, desde logo, que o termo justiça é entendido no presente ensaio como dimensão teleológica do Direito. Ao falar de dimensão teleológica do Direito tem-se em mente aquela teoria que estuda o Direito em face de suas causas finais, ou seja, o Direito aqui sendo dirigido a um fim específico, qual seja: a justiça.

Sabendo-se que a realidade humana tem começo, meio e fim, com o fenômeno jurídico não poderia ser diferente. Portanto, se em tudo há uma finalidade, o Direito, como todas as outras realidades humanas, tem que ter um fim. E esse fim (finalidade) para a teoria teleológica do Direito é simplesmente a justiça, o alvo certeiro do Direito. Assim, ao se fazer justiça através da aplicação do direito ao caso concreto, tem-se que o fenômeno jurídico atendeu perfeitamente seu objetivo maior.

Portanto, é isso que, ao menos em tese, propõe o presente artigo e a meta é levar o leitor ao entendimento de que a atual situação a que se chegou na sociedade tornou-se insustentável e sem precedente na história. 0 que se observa é 
um Judiciário “sucateado”, na UTI, e sem as condições mínimas de responder aos anseios dos cidadãos que batem às suas portas em busca da prestação jurisdicional, da tão sonhada justiça social que, da forma como se apresenta, mais parece um pesadelo que insiste em manter os cidadãos adormecidos.

\section{Direito e suas dimensões evolutivas}

Como tudo o que acontece na história, o Direito não nasceu como um produto pronto e elaborado tal qual uma mercadoria que é ofertada ao consumidor. Ao contrário, o Direito tem passado por algumas dimensões evolutivas sobre as quais se pretende falar como postulado básico para o desenvolvimento do presente ensaio.

Aa dimensões evolutivas que se pode destacar são as dimensões mais conhecidas como gerações, as quais se referem ao desenvolvimento jurídico que foi tomando corpo com o passar do tempo. O primeiro momento histórico (ou dimensão) marcante que não pode deixar de ser lembrado foi a Revolução Francesa de 1789, que com os seus ideais de igualdade, liberdade e fraternidade trouxe, na sua esteira, os direitos civis e as liberdades políticas, possibilitando, desse modo, a queda da Monarquia Absoluta.

Num segundo momento destaca-se a eclosão dos direitos sociais com a Revolução Comunista de 1917. Realizada sob o lema “pão, paz e terra”, a Revolução Soviética derrocou um dos mais poderosos e reacionários impérios de então. Os operários e camponeses dirigidos pelo Partido Comunista bolchevique tornaram-se protagonistas de uma nova era na história da humanidade - a era da luta pelo socialismo e das realizações do socialismo.

Sem a mínima pretensão de um aprofundamento sobre o tema, posto que não é esse o escopo deste texto, o que se pode dizer, pelas palavras do Professor Paulo Lopo, ${ }^{1}$ é que essa dimensão da eclosão dos direitos sociais pode ser dividida em duas vertentes: a pré-compreensão marxista e a execução leninista, ou seja, um momento histórico em que Marx foi o ideólogo e Lênin o executor. Ao que se sabe, Lênin tentou implantar um socialismo que mais mostrasse uma aproximação com a realidade, mas não conseguiu atingir seu objetivo pelo simples fato de não ter conseguido coadunar a liberdade política com a igualdade econômica. Entretanto, não se pode olvidar que a contribuição marxista e leninista foi o berçário onde foram incubados e repensados todos os padrões socioeconômicos da humanidade.

SARAIVA, Paulo Lopo. A Tetradimensionalidade do Direito. 1. ed. Pau dos Ferro/RN: Produção do autor, 2011. 
Pode-se falar, ainda, na dimensão sociológica, onde encontramos os direitos advindos do pós-guerra mundial, quais sejam o direito ao desenvolvimento econômico, à segurança internacional, à solidariedade e à paz mundial. Esses novos direitos sociais eclodem em vários lugares ao redor do mundo, tais como a África e a Ásia, culminando com a independência de vários países. Como corolário da independência desses países surge a democracia como uma dimensão jurídica do Direito, ainda que incipiente.

Por fim, não se pode obliterar a dimensão jusfilosófica, em que o Direito se manifesta nas esferas jusnaturalista, juspositivista, jus-sociológica e jusestruturalista, que é a visão do fato jurídico sob a égide do alemão Friedrich Müller, professor da Universidade de Heidelberg na Alemanha. No âmbito jusnaturalista tem-se o direito natural, que é a primeira noção jurídica que se recebe e que se inicia na própria família, onde se destacam os conceitos morais e de educação que são herdados dos pais, razão pela qual até hoje permanece o tão conhecido brocardo de que "educação vem do berço".

Sob a ótica juspositivista, observa-se a figura marcante do alemão Hans Kelsen com o seu juspositivismo jurídico. Sem aprofundamento, vale apenas destacar o que o eminente jurista Paulo Lopo ${ }^{2}$ preleciona: “... para Kelsen o direito é apenas uma ordem coativa que se situa entre dois mundos específicos: o do ser e o do dever. Nesse sistema kelseniano, entre ser e dever, as normas encontram-se ordenadas num escalonamento hierarquizado que traz no seu ápice a Constituição".

$\mathrm{Na}$ dimensão jus-sociológica o que ocupa a atenção do intérprete é o exame da eficácia normativa, ou seja, a preocupação com o real cumprimento do dispositivo legal. Para essa visão o direito tem sua gênese no fato social e a consequência natural disso é que, sem a devida valoração do fato social, qualquer tentativa de se fazer justiça já está fadada ao fracasso e não passa de um desvio no atendimento da justiça que se espera. Aqui, o que se reveste de importância é a análise sociológica para que se tenha a verdadeira e real percepção do direito e, como resultado disso, a verdadeira justiça. Portanto, essa corrente parte da visão de que os clamores sociais devem ser a força motriz e o fato gerador de toda e qualquer norma jurídica que venha a viger na sociedade.

\section{Direito sob o viés positivista}

Antes de qualquer palavra acerca do tema em comento, é conveniente delimitar o que se entende por positivismo. O propósito, apesar de não ser a citação

2 SARAIVA, Paulo Lopo. A Tetradimensionalidade do Direito. 1. ed. Pau dos Ferro/RN: Produção do autor, 2011. p. 69. 
de definições, não poderia se furtar de definir o termo positivismo na acepção que se emprega no presente texto no afã de se evitar uma compreensão errônea daquilo que se quer abordar. E para tal, nada mais justo que invocar o próprio jurista alemão Hans Kelsen, que é tido como um dos maiores, senão o principal, expoente do positivismo jurídico. O pensamento central de Kelsen ${ }^{3}$ é a Teoria Pura do Direito, onde ele assim se expressa:

Quando a si própria se designa como "Pura" teoria do Direito, isto significa que ela se propõe garantir um conhecimento apenas dirigido ao direito e excluir deste conhecimento tudo quanto não pertença ao seu objeto, tudo quanto não se possa, rigorosamente, determinar como Direito. Isso quer dizer que ela pretende libertar a ciência jurídica de todos os elementos que lhe são estranhos.

Portanto, para Kelsen, o direito deveria ser entendido como norma, estando livre de qualquer concepção social ou valorativa. O cerne da sua obra Teoria Pura do Direito é libertar a ciência jurídica de todos os elementos que não the são próprios, ou seja, libertar a ciência jurídica de elementos estranhos à sua alçada (pelo menos ao seu ver) e com isso o estudioso caminha para especificar uma ciência que não se confunda com a psicologia, a sociologia, a política e a moral, é dizer, uma ciência autóctone.

Kelsen faz uma análise toda pessoal do Direito como sendo apenas um conjunto de normas representadas por prescrições que revelam a categoria do "dever ser", e desse modo relega os fatos a uma escala de jurídico ou antijurídico. Para esse jurista não há espaço para mais anda entre a juridicidade a antijuricidade. Esse é um espaço fechado que não permite nenhuma flexibilidade. Usando as próprias palavras de Kelsen:4 "Esta significação jurídica não pode ser percebida no ato por meio dos sentidos, tal como nos apercebemos das qualidades naturais de um objeto, como a cor, a dureza, o peso".

Neste contexto, Kelsen observa que a norma é um produto da vontade, elaborada com a finalidade de regular a conduta humana, e que funciona como um esquema de interpretação. O ponto-chave do pensamento kelseniano se concentra na interpretação da norma. Não é sem razão que o próprio Kelsen prolata, ainda, que "o juízo em que se enuncia que um ato de conduta humana constitui um ato jurídico ou antijurídico é o resultado de uma interpretação".

3 KELSEN, Hans. Teoria Pura do Direito. Tradução João Baptista Machado. 6. ed. São Paulo: Martins Fontes, 1999, p. 11.

4 KELSEN, Hans. Teoria Pura do Direito. Tradução João Baptista Machado. 6. ed. São Paulo: Martins Fontes, 1999, p. 14. 
Na continuidade do seu pensamento é válido ressaltar o que o autor teoriza acerca da norma: "a norma que empresta ao ato o significado de um ato jurídico ou antijurídico é ela própria produzida por um ato jurídico, que por seu turno recebe a sua significação jurídica de outra norma". ${ }^{5}$

Aqui se faz necessário destacar que para o positivismo a norma tem validade não pelo sentido de ser justa ou injusta, mas pelo simples fato de estar ligada a outra norma considerada superior, que ele denomina de norma fundamental. É a partir desse conceito metodológico da norma fundamental que o jurista consegue criar uma sistematização de toda a ordem jurídica.

Eis a razão pela qual, quando se discute Kelsen, não se pode perder de vista o foco da questão principal do seu pensamento, que é a validade da norma jurídica, sendo esse um dos aspectos mais importantes sob a ótica da teoria kelseniana. Para que se possa falar em validade da norma, sempre se deve pensar que tal validade decorre obrigatoriamente da sua ligação a outra norma, sendo a norma fundamental aquela considerada hierarquicamente superior e sempre editada por um ato normativo determinado. Em outras palavras, a norma é quem valida a norma: eis a síntese do pensamento positivista.

Portanto, para a teoria positivista o Direito é um conjunto de normas que regulam a conduta humana e essas normas, por sua vez, quando legitimamente válidas, adquirem poder para estabelecer sanções, pois, em razão da sua estrutura, é caracterizada como uma ordem coercitiva. Nesse ponto, chega-se à delimitação do conceito de direito sob o viés positivista a que se propõe o presente texto, onde se entende a norma como uma ordem coercitiva e que só tem validade se estiver umbilicalmente ligada a outra norma. Tal entendimento é imprescindível quando se for tratar da possibilidade da aplicação da Teoria Estruturante do Direito em nosso atual contexto jurídico. O Direito contemporâneo, como já mencionado, já não mais atende aos anseios sociais por justiça, e por conta dessa realidade padece de um reexame estrutural com vistas a uma nova dimensão jurídica: a efetividade da justiça.

Nesse ponto há que se falar nos profissionais do Direito como "efetivadores" do Direito e não apenas "operadores" do Direito. Quando for tratado acerca da questão da vigência e eficácia da norma jurídica, o tema será retomado. Por fim, as sociedades complexas e plurais já não suportam mais o conceito do positivismo jurídico, onde a norma é configurada como uma espécie de moldura, caracterizada pela mera subsunção de um fato concreto a uma norma. 0 que se observa na sociedade é que nem sempre a simples subsunção da norma ao fato

5 KELSEN, Hans. Teoria Pura do Direito. Tradução João Baptista Machado. 6. ed. São Paulo: Martins Fontes, 1999, p. 22. 
concreto é suficiente para atender ao anseio de justiça preconizado pelos conflitos instaurados. Até mesmo porque o que se observa é que existem determinados fatos concretos semelhantes na sociedade que, na grande maioria das vezes, não podem ser resolvidos com a simples aplicação e subsunção da mesma norma, dada a complexidade dos conflitos e das relações interpessoais.

Portanto, no conceito positivista de Kelsen não sobra espaço para a análise social, fatos sociais ou até mesmo quaisquer outros conceitos subjetivos que levem a uma interpretação de qualquer natureza. Para o positivismo a norma posta é a mais adequada e também é a única capaz de atender a coercitividade necessária ao seu cumprimento, razão pela qual vem eivada de sanção pelo seu não cumprimento, que a todos é imposta indistintamente. E dentro desse conceito hermético e fechado, sem espaço para interpretação e aplicação aos fatos sociais, o positivismo jurídico tem se distanciado cada vez mais do homem moderno.

o que se sabe, ao certo, é que as normas surgem dos fatos sociais que ocorrem dentro da convivência coletiva, e isso, por si só, já denota um afastamento do direito positivo ao conceito de justiça que se espera dentro da sociedade. Para a população pouco importa a existência rígida e fria da norma e sua subsunção ao caso concreto se essa mesma norma for capaz de propiciar a tão almejada justiça. O povo, de um modo geral, sequer tem noção do significado das normas jurídicas, quanto menos sua aplicação e subsunção ao caso concreto. 0 que a sociedade precisa é de justiça, e a norma não tem sido capaz de viabilizá-la de uma maneira concreta e eficaz, por mais bem elaborada que seja.

E aqui, nesse ponto, foca-se o olhar para um outro ponto crucial, e para o qual muitas vezes não se tem resposta, qual seja: é justo porque está ordenado, ou está ordenado porque é justo? Não se tem a pretensão de dar uma resposta a essa pergunta, não obstante ela ingressa aqui no presente texto como um impulsionador social ao fato de que a sociedade hodierna ainda clama por justiça, e nem sempre a norma pura e simples aplicada ao caso concreto traduz a ideia de justiça. É dentro dessa premissa básica que se passa a analisar uma segunda proposta da norma jurídica, que é a proposta do jurista alemão Friedrich Müller.

\section{A proposta de Friedrich Müller}

Antes de qualquer coisa, é digno de nota que a análise de uma obra dessa envergadura como a do jurista alemão Friedrich Müller seria uma tarefa hercúlea e impossível de ser tratada em um tópico de um artigo. 0 articulista se verga ante a grandiosidade do pensamento do jurista e tem em mente apenas uma análise perfunctória (na acepção mais literal do vocábulo). 
O jurista e filósofo Friedrich Müller é um profundo conhecedor do Brasil e exatamente por conta disso é considerado na atualidade como um estudioso exemplar do modelo legislativo e judiciário de países como o Brasil. Entretanto, para que Müller chegasse a esse sólido grau de conhecimento, ele teve que superar os limites do positivismo e do nacionalismo jurídico, o que fez com louvável sucesso, desenvolvendo um método interpretativo chamado Teoria Estruturante do Direito. Só para se ter uma pálida ideia da importância do jurista para o Brasil, suas contribuições não se limitaram apenas a textos ou doutrinas, mas concretizaram-se com a Emenda Constitucional $n \stackrel{0}{4}$, que ficou conhecida como a que reformou o Poder Judiciário.

De acordo com Bruno, ${ }^{6}$ Friedrich Müller considera que o texto de um preceito jurídico positivo é apenas uma pequena parte descoberta do iceberg normativo, que, após interpretado, revela o respectivo programa normativo. Ou seja, o texto da lei, por si só, corresponde apenas a uma parte da norma, sendo a outra parte encontrada a partir da interpretação do enunciado normativo.

A proposta do jurista alemão deve ser analisada sempre com o foco na ideia de justiça, que é o objeto maior deste artigo e que, ao menos em tese, apresenta uma proposta mais viável aos apelos de justiça que vêm sendo ecoados no decorrer da história. Sua proposta se traduz na forma mais viável da aplicação da justiça, uma vez que Friedrich Müller, ${ }^{7}$ mais que descrever a norma, tem a preocupação de interpretar a norma e viabilizá-la ao contexto fático da sociedade. Em que pese a importância do pensamento do direito positivo esposado por Hans Kelsen e seu legado ao mundo jurídico, entende-se que a proposta de Friedrich Müller atende com mais presteza às necessidades da sociedade moderna por justiça.

Por essa razão, é fundamental que nesse ponto se faça um contraponto entre a Teoria Pura do Direito de Kelsen e a Teoria Estruturante do Direito do professor Friedrich Müller. Enquanto a teoria positivista de Kelsen se ocupa em descrever a norma, a Teoria Estruturante do Direito do professor Friedrich Müller torna viável a interpretação e a concretização da norma. Para se entender melhor a proposta do jurista e professor alemão, será utilizado um exemplo prático daquilo que o professor Friedrich Müller quer transmitir com a sua teoria, uma vez que, por ser uma maior aproximação do Direito com as realidades sociais, infelizmente essa teoria do jurista alemão tem sido mal interpretada.

6 Bruno Brito (23 de setembro de 2009). Esmape traz palestra do jurista alemão Friedrich Müller para o Recife. Tribunal de Justiça de Pernambuco. Disponível em: <http://www.tjpe.jus.br/noticias_ascomSY/ ver_noticia.asp?id=6281>. Acesso em: abr. 2012.

7 MÜLLER, Friedrich. O Novo Paradigma do Direito - Introdução à teoria e metódica estruturantes do direito. São Paulo: Revista dos Tribunais, 2007. 
Para essa abordagem serão usadas as considerações do Prof. Dr. Paulo Lopo Saraiva, ${ }^{8}$ uma vez que refletem, de uma maneira clara, todo o escopo esboçado pelo jurista alemão:

\begin{abstract}
... na miragem mülleriana, o direito positivo é uma norma-texto (input), um enunciado jurídico, que será operacionalizado pela normaprograma (esfera da hermenêutica), norma-âmbito (esfera do fato social). A interconexão dessa norma produzirá a norma jurídica, genérica e abstrata, de conseguinte, impotente para a realização jurídica. Somente após a decisão política, surge a norma de decisão (output), essa sim concretizadora do direito, portanto, realizadora da justiça, de vez que a finalidade do Direito é realizar a justiça.
\end{abstract}

Observa-se, pelas palavras citadas, que a intenção da Teoria Estruturante do Direito do professor Friedrich Müller é ir além da norma dogmática, que até hoje não tem conseguido atingir seus objetivos em face da questão estrutural no que diz respeito ao binômio vigência e eficácia da lei, que será tratada posteriormente.

E o professor Paulo Lopo ${ }^{8}$ continua seu argumento com um exemplo prático, e que nos traz uma noção mais exata do que está a se tratar quando nos traz o seguinte argumento: a Constituição brasileira prescreve que "a educação é direito de todos e dever do Estado". Temos aqui, inicialmente, uma norma texto, um input do sistema jurídico. Ao se interpretar essa norma por meio da norma-programa, à vista do fato social, por exemplo, a educação para Pedro, que é a norma-âmbito, constrói-se a norma jurídica, genérica e abstrata, qual seja, todos têm direito à escola. No entanto, Pedro, que tem direito à escola por meio da norma genérica e hipotética, continua sem escola por alguns fatores sociais, seja porque não existe a escola, ou não há professores ou até mesmo porque ele não pode adquirir material escolar para frequentar a escola. Nesse caso simples e prático, observa-se que a norma jurídica, per se, não realiza direito algum. O simples fato de estar positivado não concede a Pedro o direito efetivo de ir à escola.

Percebe-se, portanto, que a norma jurídica é impotente à efetivação do direito, razão pela qual sempre deve haver uma decisão específica, aqui chamada pelo jurista de 'norma de decisão', que será a responsável para dar a resposta adequada à finalidade essencial e primordial do direito que é a justiça. Destarte, nota-se que não é sem razão que o título deste ensaio destaca a ideia de justiça sob a ótica da teoria desse pensador alemão, uma vez que se entende que a

8 SARAIVA, Paulo Lopo. A Tetradimensionalidade do Direito. 1. ed. Pau dos Ferro/RN: Produção do autor, 2011. p. 62. 
atual conjuntura jurídica esposada em nosso país já não traduz o verdadeiro e real conceito de justiça que é esperado pela sociedade de um modo geral. E a prova inequívoca dessa realidade é um Poder Judiciário sucateado, abarrotado de processos, e despreparado para dar as devidas respostas à sociedade. Ao fazer uso das expressões 'entrada' (input) e 'saída' (output), o professor Paulo Lopo ${ }^{9}$ consegue detectar o principal foco da Teoria Estruturante do Direito e, por meio de uma linguagem clara e acessivel aos leitores, consegue transmitir a essência do pensamento de Friedrich Müller, sendo esse o papel central de quem se propõe a estudar o fenômeno jurídico com toda sua complexidade. Não basta adotar essa ou aquela teoria como determinante e seguir em frente. O mais coerente é fazer uma análise detalhada de cada teoria "per se" e adentrar na complexidade das relações interpessoais para que se observe qual a teoria mais adequada a cada caso específico.

Há momentos em que a simples aplicação da norma ao fato concreto puro e simples já é suficiente para resolver a demanda por justiça. Entretanto, há outros casos em que há que se falar em interpretar a norma e fazer sua aplicação correta ao caso concreto, sendo certo que para isso deverá ser levado em conta não apenas a norma em si, o enunciado do texto normativo, entretanto, todo um contexto social em que essa norma está inserida. Esse é o foco central da Teoria Estruturante do Direito proposta por Friedrich Müller, o que, por si só, já se constitui em uma tarefa hercúlea, uma vez que as relações sociais têm passado por profundas e complexas transformações ao longo da história, de sorte que o que se observa hoje é totalmente diferente e inusitado de tudo o que já se vivenciou até agora.

Foi citado apenas o exemplo de Pedro, a quem a Constituição federal concede o direito de ir à escola. Entretanto, poder-se-ia mencionar os inúmeros casos de pessoas carentes sem acesso à justiça, os sem-teto que não têm direito a uma moradia digna, bem como os mais desvalidos, que necessitam de uma medicação de alto custo e têm o dissabor de ver seu parente morrer à míngua por falta de recursos para bancar essa medicação, enquanto as torneiras dos cofres públicos continuam abertas à corrupção e aos desmandos dos que deveriam tutelar o direito da patuleia.

Entende-se que a preocupação de todo aquele que estuda o sistema jurídico como um todo é a busca da relação do direito com o contexto social em que ele está inserido, uma vez que não há que se falar em direito e normas jurídicas sem sociedade e coletividade de pessoas. O que se pode afirmar de concreto é que, ao

9 SARAIVA, Paulo Lopo. A Tetradimensionalidade do Direito. 1. ed. Pau dos Ferro/RN: Produção do autor, 2011. p. 69. 
se falar de justiça e aplicação da lei ao caso concreto, a ideia que se tem hoje é que não há justiça na sociedade. Esse é o atual momento em que se vive no nosso país e ao redor do mundo, com os entes encarregados de tutelar os interesses do cidadão totalmente desacreditados, e o Poder Judiciário preso a um legalismo ímpar, sem os instrumentos adequados e eficazes para conceder a tão almejada prestação jurisdicional.

Não cabe espaço aqui para apontar o culpado ou os culpados por tal situação, se é que se pode mencionar alguma coisa nesse sentido. Ao contrário, o que se pretende é fazer uma análise séria e comprometida com uma mudança de rumo e de direção, uma vez que apenas apontar o problema sem a sua devida solução em nada atenua a dor e o sofrimento experimentado pela população. 0 atual momento social é crítico e complexo, e o Poder Judiciário, como representante do Estado, precisa se adequar e buscar as ferramentas necessárias ao atendimento da prestação jurisdicional, uma vez que o próprio Estado avocou para si a responsabilidade da aplicação da justiça, em detrimento da antiga justiça privada, é dizer, a justiça pelas próprias mãos, que vitimou tantas vidas inocentes.

Fato é que a Teoria Estruturante do Direito sob a ótica do jurista Friedrich Müller ${ }^{10}$ é uma proposta que visa ampliar os limites e as possibilidades da ciência jurídica, tradicionalmente conhecida por Direito, ante o grande desafio que a sociedade pós-moderna nos reserva, qual seja, a impossibilidade da entrega da prestação jurisdicional ao cidadão que clama por justiça, ante um Poder Judiciário engessado, frio e totalmente legalista.

Essa proposta, consoante o próprio autor da teoria, Friedrich Müller, prolata em seu livro Teoria Estruturante do Direito I, nada mais é que uma adequação das normas jurídicas às necessidades da sociedade hodierna, que tem passado por grandes e rápidas mudanças, de tal modo que o atual modelo que vem sendo proposto ao longo dos anos já não mais responde à altura as necessidades desse homem da pós-modernidade, cujos tempos modernos não conseguiram suprir sua necessidade por justiça.

Portanto, a teoria de Friedrich Müller ${ }^{11}$ tratada no presente artigo, embora não se trate de algo novo, inusitado, mesmo assim traz em seu bojo alvíssaras de esperança de que alguma mudança seja dada no atual status quo que ora se observa, com um Direito que ingressa em uma via extremamente legalista e operadores do Direito engessados pelas normas jurídicas vigentes, o que leva, invariavelmente à negação do sagrado direito constitucional de acesso à justiça por parte do cidadão.

10 MÜLLER, Friedrich. Teoria estruturante do Direito I. São Paulo: Revista dos Tribunais, 2008.

11 MÜLLER, Friedrich. Interpretação e concepções atuais dos direitos do homem. Anais da XV Conferência Nacional da Ordem dos Advogados do Brasil, v. 8, mar. 2006. 


\section{Atual momento jurídico}

Por tudo o que já foi falado, é notória a crise que se instalou no Judiciário brasileiro, sendo essa uma das razões pelas quais o cidadão hodierno anda desconfiado e já não vislumbra a tão almejada justiça. O Poder Judiciário se encontra tão abarrotado de processos que a concessão da justiça, quando ocorre, geralmente é intempestiva e sem nenhum efeito prático ao autor da lide. Na maioria dos casos são os herdeiros que findam por ver cumprida a justiça na vida do pai, mãe, irmão, ou tia e tio, de há muito falecidos. Nesse ínterim é válido relembrar aqui o que já dizia Rui Barbosa: ${ }^{12}$ “Justiça tardia não é justiça, é injustiça manifesta. Porque a dilação ilegal nas mãos do julgador contraria o direito das partes, e, assim, as lesa no patrimônio, honra e liberdade".

O grande problema que se apresenta é que em nosso país temos uma crise estrutural disseminada e manifesta, o que acaba gerando uma cadeia desenfreada de reações as mais adversas. O festival de corrupção promovido pelos políticos brasileiros, que, acreditando piamente na impunidade, usam e abusam do direito de praticar improbidades com o erário, é uma realidade para a qual não se pode mais fechar os olhos. O problema é que, raras exceções, quando trata de processos que envolvem políticos poderosos, o atual Sistema Judiciário, extremamente lento, acaba gerando a sensação de impunidade restando a certeza, quase inexorável, de que a maioria deles não serão alcançados pela Lei, o que finda mesmo por acontecer.

Diante desse panorama anárquico e de caos, o cidadão se pergunta e se questiona até quando continuará assistindo a tudo isso impotente, entorpecido pelos desmandos daqueles que deveriam zelar pela lei, proteger e criar mecanismos de defesa. A pergunta que o cidadão se faz, atônito e sem direção, é se há possibilidade ou perspectiva de alguma mudança dessa atual conjuntura, que, pelo menos ao que parece, insiste em se perpetuar em nosso país.

Nesse contexto, vale destacar as palavras de Lenio Streck, em seu livro Hermenêutica Jurídica e(m) Crise, que assim prolata: “... de 1986 a 1995, somente 5 dos 682 supostos crimes financeiros apurados pelo Banco Central resultaram em condenações em 1a instância na Justiça Federal". Segundo o próprio Lenio Streck ${ }^{13}$ o Direito não consegue preencher essa lacuna existente em nosso ordenamento jurídico, que perpetua a política da impunidade, não por falta de previsão no Judiciário, senão por conta do que ele chama de uma "crise de modelo".

Essa crise de modelo esposada pelo autor nada mais é que um apego demasiado ao positivismo jurídico, onde para cada situação específica se cria uma

12 BARBOSA, Ruy. Oração aos moços. Marcelo Módolo (Org.). São Paulo: Hedra, 2009.

13 STRECK, Lenio. Hermenêutica Jurídica $e(m)$ Crise - uma exploração hermenêutica da construção do direito. p. 28. 
lei, como se a simples criação da lei fosse a resposta para a solução final do problema. Essa, na realidade, trata-se de uma herança que foi herdada do direito positivo e deixa a falsa sensação de que a mudança legislativa é a saída para se mudar determinadas situações de crise no Brasil. Na maioria das vezes são situações que se tornaram insustentáveis na sociedade e a saída se dá, via de regra, pela criação de mais uma lei, que acaba que não resolve nada.

Só para se ter uma ideia mais concreta do que se fala, pode-se citar a Lei no 12.846/2013, que é a tão famosa Lei Anticorrupção. Em que pese a necessidade de se dar um basta nos escândalos de corrupção e no crescimento desenfreado do uso do erário em proveito próprio, essa lei anticorrupção nasce em dois momentos distintos: por um lado, o contexto de corrupção que tem devastado o país nesses últimos anos, por outro lado, a pressão exercida pelos movimentos de indignação popular face ao que se observa cotidianamente. O fato é que logo que surge um determinado escândalo na sociedade, quando menos se espera, de imediato este já é passado, uma vez que surgiu outro escândalo ainda maior. Essa é a atual realidade do Brasil, e com isso se vai criando a sensação de impunidade que hoje se observa. Ser honesto hoje passou a ser a exceção e não a regra geral e, só para se ter uma pálida ideia, há 50 anos era orgulho de qualquer família brasileira ter um membro atuante no serviço público em qualquer das esferas, seja municipal, estadual ou federal, uma vez que ser servidor público era uma honra na sociedade da época. Por seu turno, por conta da corrupção desenfreada, o quadro hoje, infelizmente, está deturpado, servidor público tornou-se sinônimo de desonestidade e preguiça. Uma pecha injusta e inadequada, pois é fato que ainda há servidores públicos honestos e íntegros em nosso país.

Pois bem, é diante desse contexto que se passa a pensar na Teoria Estruturante do Direito de Friedrich Müller e como ela pode ser valiosa para o nosso ordenamento jurídico. Entretanto, antes de qualquer menção sobre o tema, é bom que se repita que toda e qualquer teoria do direito deve ser analisada no seu contexto específico e dentro da complexidade das relações jurídicas que se apresentam. De nada adianta aplicar essa ou aquela teoria se não vier empenhada com a responsabilidade de se fazer uma adequação e um estudo sério de cada caso concreto ao objeto a que se destina, consoante já mencionado.

\section{Aplicação da Teoria Estruturante do Direito em nosso atual contexto jurídico}

Após essa breve análise da teoria de Friedrich Müller e do atual momento jurídico por que passa o nosso país, cumpre destacar a aplicação dessa teoria em 
nosso atual contexto jurídico face a um ordenamento marcantemente positivista como o nosso. Já foi apontado que o positivismo leva em conta a dogmática jurídica, não abrindo espaço a uma interpretação e aplicação prática e mais real à realidade do cidadão. Eis um dos pontos centrais que explica a razão pela qual o cidadão não consegue a prestação jurisdicional tão sonhada e almejada e, como já foi mencionado, a justiça passa a ser uma mera utopia.

Como decorrência disso, muitas vezes o juiz vê-se escravo da lei e impedido de aplicar a justiça, uma vez que nem sempre a aplicação correta da norma jurídica significa que foi feita justiça. A propósito disso, há uma peça de Shakespeare denominada 'Medida por Medida' que serve para exemplificar bem o que se fala. Tomar-se-ão alguns aspectos dessa peça shakespeariana apenas como exemplo daquilo que se observa nos dias atuais, pois sendo uma peça teatral, onde se fala de atores e personagens, mesmo assim se ajusta perfeitamente ao que se pretende abordar.

A peça, que foi escrita por volta de 1603 , embora seja tida como comédia, na realidade trata sobre um tema muito atual, que é o poder que corrompe. Por essa razão, a peça Medida por Medida trata de conceitos muito conhecidos da sociedade moderna, como justiça, corrupção, equidade, abuso de poder, dentre outros, como o apelo sexual, a volúpia e outros sentimentos conflitantes que afligem a todos indistintamente.

A peça narra o momento em que o Duque de Viena precisa se ausentar do país por um período determinado e deixa no poder o juiz Ângelo, que é conhecido no país pela sua rigorosidade em cumprir as leis, em especial o seu zelo pela moralidade, o que o tornou conhecido por punir com o rigor da lei os que cometem fornicação e adultério na cidade, por isso mesmo sendo temido por todos os cidadãos de Viena.

Nesse tempo em que está à frente da cidade, ocorre um incidente com um casal de jovens que irá testar até onde o poder pode levar a pessoa. Um casal de enamorados, Julieta e Cláudio, no ardor da paixão não consegue esperar os trâmites legais para o casamento e findam por terem uma relação sexual indevida. O juiz Ângelo, com seu ímpeto pela moralidade, finda por separar o casal e confina Cláudio ao cárcere sumariamente, sentenciando-o à morte, num gesto de moralidade pública que sirva de exemplo a toda a sociedade vienense.

Cláudio, condenado peremptoriamente e sem perdão, apela à sua irmã, uma noviça, que interceda a Ângelo por ele, alegando que o casamento se dará logo em breve. Disposta a ver seu irmão livre, a noviça Isabella se dirige até o juiz Ângelo para suplicar pelo irmão, argumentando que o que aconteceu foi apenas um arroubo da juventude e que os dois dentre em breve se casarão e serão marido e mulher. Tudo em vão, uma vez que o juiz Ângelo mostra-se irredutível na sua 
decisão e não aceita qualquer intermediação no sentido de libertar Cláudio. A desculpa usada por Ângelo é que não foi ele quem prendeu e condenou o irmão de Isabella, entretanto a lei foi a responsável por isso, e que ele só podia fazer o que estava na lei. Entretanto, ao travar o diálogo com Isabella, o juiz Ângelo percebe que se trata de uma bela espécime humana, uma mulher linda e deslumbrante, e que além de tudo era virgem, eis que havia feito os votos do noviciado. Ao perceber a beleza de Isabella, o juiz Ângelo propõe que pode libertar seu irmão, desde que ela se deite com ele.

Observa-se, no texto dessa peça, que o juiz Ângelo, que se dizia escravo e apenas cumpridor da lei, passou de escravo a livre para interpretar a lei a seu bel-prazer, desde que seus instintos e desejos sexuais fossem satisfeitos pela noviça Isabella. Ao se ler essa peça de Shakespeare, não se sabe ao certo o que inspirou ou motivou o autor a escrevê-la. Não se sabe se foi para zombar da justiça dos nobres e poderosos da época, expondo-Ihes a fraqueza de julgamento, ou foi para mostrar que diante dos impulsos mais comezinhos o homem não consegue ter controle total. Pouco importam os motivos e as razões do autor. 0 certo é que a peça remonta a temas atualíssimos, como corrupção, jogo de poder, bem como os dilemas morais e éticos vivenciados por todas as pessoas, seja na vida pública ou privada.

A peça reflete exatamente o que se vivencia em nossa sociedade hoje, onde os que deveriam zelar pela justiça, pela moral e pela ética são os primeiros a darem maus exemplos, agredindo todos esses conceitos, lançando na lama as leis, esquecendo completamente que a cada comando normativo existe um liame social atrelado a ele, razão pela qual a lei, repete-se, deve ser aplicada ao caso concreto, dentro do contexto social adequado a essa norma. Dissociar a norma pura e simples do seu contexto social é simples pretexto para fechar os olhos à realidade que se observa. Por outro lado, uma aplicação concreta da norma ao caso concreto, com todas as vertentes sociais que envolvem a situação fática específica, nada mais é que a correta aplicação do Direito ao caso concreto. Não uma mera subsunção sem nexo ou causa, mas uma aplicação escorreita da lei. Essa é a proposta da Teoria Estruturante do Direito de Friedrich Müller, sendo a ótica mais apropriada para se abordar e enfrentar a justiça nessa sociedade moderna, ou pós-positivista.

Em que pese a peça de Shakespeare tratar de uma realidade do século XVII, não se pode olvidar que os fundamentos presentes na obra têm reflexos na sociedade moderna, de tal modo que os mesmos conceitos de poder e de direito usados de uma maneira incoerente e errada são os mesmos conceitos de que hoje se lança mão para desvirtuar o direito e a justiça, uma vez que em nome da justiça e do direito o que se observa é que muitos desmandos têm sido praticados 
na sociedade. Eis a razão pela qual o povo continua desacreditado e sem perspectivas, pois o direito e a lei são usados como meros pretextos e com isso inúmeras portas têm sido abertas às injustiças.

Portanto, a aplicação da Teoria Estruturante do Direito do jurista alemão em nossa sociedade contemporânea traduz melhor a ideia de justiça preconizada pelo Poder Judiciário e tão esperada pela população como um todo. Sendo, como já se observou, uma teoria que modela a norma jurídica à realidade social vivenciada pela coletividade, a aplicação da teoria de Friedrich Müller ${ }^{14}$ tem o condão de diminuir as diferenças abismais que existem hoje entre o efetivo direito do cidadão e a prestação jurisdicional que Ihe tem sido prestada. Um estudo mais aprofundado e detalhado sobre essa teoria pode ser uma saída para um Poder Judiciário mais justo e mais próximo do povo, uma vez que a realidade tem dado mostras do quanto esse órgão jurisdicional se encontra distanciado do cidadão, pelos motivos já apresentados e tantos outros que poderiam ser citados. Entende-se que uma aproximação mais adequada dessa teoria seria uma oportunidade para se repensar a questão da vigência e efetividade da lei, e o respeito à dignidade da pessoa humana tão decantado na Constituição Federal.

\section{Vigência e efetividade da norma jurídica}

Falar de vigência e eficácia da norma jurídica é trazer à baila um assunto que perpassa o entendimento do homem mediano. As discussões modernas sobre esse tema trazem à tona os desafios a que são submetidos os operadores do Direito na sociedade pós-moderna. Aliás, seria interessante se falar nos dias atuais em "efetivadores do Direito" mais que o termo "operadores do Direito". A razão disso é subjacente e jaz no fato de que o homem moderno, hoje mais que nunca, busca a todo custo a efetivação do seu direito, a justiça que nunca chega. O termo "operadores do Direito", que se tornou lugar comum na sociedade, remonta à ideia de algo mecânico, como uma máquina que se opera automaticamente, o que não corresponde à prática jurídica. O Direito, por ser dinâmico e sofrer várias mutações, jamais pode ser visto e executado como uma máquina, onde o operador programa e deixa que o processo automático siga seu curso. 0 Direito é tudo menos isso.

Ao falar em "efetivadores do Direito" tem-se em mente a necessidade que o Direito contemporâneo trouxe no sentido de uma construção da interpretação da

14 MÜLLER, Friedrich. Métodos de trabalho do Direito Constitucional. Trad. de Peter Naumann. 2. ed. São Paulo: Max Limonad, 2004. 
lei que possa refletir o caráter inclusivo do Direito, face ao Estado Democrático de Direito a que chegou a sociedade pós-moderna, e devidamente preconizado pela Constituição Cidadã de 1988. Assim arrazoando, podem-se citar pensadores como Gadamer, Habermas, Alexy, Raz, Günther e Dworkin, que são profundos pesquisadores do fenômeno jurídico, e que trazem como linha mestra de suas pesquisas essa exigência do Direito contemporâneo, qual seja uma construção interpretativa da lei, interpretação esta inclusiva e satisfativa ao homem moderno. A busca pela prestação jurisdicional efetiva passou a ser um alvo perseguido pelo homem moderno e tem se intensificado de uma forma tão grande que podemos dizer, sem medo de errar, que já faz parte das suas necessidades básicas.

O assunto é por assaz complexo uma vez que cada caso concreto apresenta sua peculiaridade específica e isso demanda um maior esforço do "efetivador do Direito", sendo certo que a discussão não se trata apenas de normas e princípios, ao contrário, vai muito além, pois envolve valores, regras e, acima de tudo, uma análise criteriosa do atual contexto histórico em que nos encontramos. Sem essa análise conjuntural e múltipla não há que se falar em justiça equânime e justa, embora pareça um pleonasmo.

Ronald Dworkin, ${ }^{15}$ em uma crítica ao positivismo jurídico, e partindo de sua ideia de integridade do Direito, propõe um modelo teórico que tem como escopo apresentar uma resposta adequada à questão da interpretação. O positivismo é tão dogmático que, para o filósofo americano, “a lei frequentemente se torna aquilo que o juiz afirma".

Pois bem, é exatamente esse dogmatismo, e, por que não dizer, a intolerância de determinados juízes, que tem feito com que a justiça não seja feita de um modo mais concreto, ficando apenas no mundo das ideias e dos ideais a serem alcançados. Hoje, mais do que nunca, repousa na mente da sociedade o binômio entre vontade e possibilidade, ou seja, é a eterna dúvida se a efetividade do direito e a consequente esperada justiça não têm sido possíveis por falta de vontade dos que trabalham na seara do Direito.

Sem querer fugir ao tema proposto neste ensaio, vale apenas destacar em rápidas pinceladas a ideia do que seja essa teoria da integridade do Direito em Dworkin. Para esse autor não há como negar as inúmeras controvérsias que existem na jurisprudência e na doutrina, e ressalta que as divergências por parte dos juízes não ocorrem apenas no que diz respeito aos fatos articulados, no entanto, há uma grande divergência no sentido da aplicação da norma jurídica. Desse modo, para Dworkin, ${ }^{16}$ grande parte do que se discute no Poder Judiciário pelos juízes trata-se de teoria e não de experiência ou fatos alegados pelas partes.

15 DWORKIN, Ronaldo. O império do direito. São Paulo: Martins Fontes, 2003. p. 14.

16 DWORKIN, Ronaldo. O império do direito. São Paulo: Martins Fontes, 2003. p. 56. 
Portanto, mesmo reconhecendo as divergências encontradas entre os juízes, o método interpretativo de Dworkin visa ampliar a norma jurídica na prática para uma visão mais ampla de aplicação da lei. Desse modo, a visão do Direito como integridade (levando-se em conta o peso dos princípios), que é a base da sua teoria, seria capaz de impor ao juiz uma racionalidade, quando do seu julgamento, de tal modo que o próprio juiz seria compelido a tomar uma decisão que levasse a uma solução contrária àquela que ele adotaria caso sua preferência prevalecesse.

A teoria interpretativa de Dworkin entende que essas divergências encontradas na prática jurídica não são causadas pela abertura das normas ou dos comandos normativos legais. Ao contrário, tais discrepâncias divergentes surgem porque os argumentos dos juízes caminham na direção de que uma interpretação diversa seria mais coerente com os princípios encontrados na prática jurídica, o que não corresponde à realidade. A esse respeito, o próprio Dworkin ${ }^{17}$ assinala que a abstração e a ambiguidade encontradas em alguma palavra ou expressão do comando normativo só tornarão essa norma confusa se "houver, pelo menos, uma dúvida sobre se a lei representaria um melhor desempenho da função legislativa se interpretada de um modo, e não de outro modo".

Portanto, o pensamento de Dworkin parte do pressuposto de que o Direito é interpretativo. Assim sendo, os juízes devem decidir o que é o Direito por intermédio da interpretação. Com isso, no pensamento de Dworkin, as teorias gerais do Direito são, na realidade, interpretações gerais de nossa própria prática judicial. ${ }^{18}$ É por essa razão que dentre as concepções interpretativas que Dworkin considera, tais como o "pragmatismo jurídico", o "convencionalismo" e o "direito como integridade", ele destaca essa última como a que melhor explica o que é o Direito. Para Dworkin, o Direito como integridade, sendo visto pela ótica da equidade, justiça e devido processo legal que uma dada sociedade colocou em vigor, seria capaz de oferecer uma melhor adequação da nossa prática jurídica como um todo, eis que a norma não vem divorciada dos demais aspectos que a cercam.

Por essa razão, o autor entende, ainda, que o conceito de direito é definido pela atitude, razão pela qual assim se expressa:

É uma atitude interpretativa e auto-reflexiva, dirigida à política no mais amplo sentido. É uma atitude contestadora que torna todo cidadão responsável por imaginar quais são os compromissos públicos de sua sociedade com os princípios, e o que tais compromissos exigem em

17 DWORKIN, Ronald. M. O Império do Direito. Tradução de Jefferson Luiz Camargo. São Paulo: Martins Fontes, (1999a). p. 422.

18 DWORKIN, Ronald. M. O Império do Direito. Tradução de Jefferson Luiz Camargo. São Paulo: Martins Fontes, (1999a). p. 488. 
cada nova circunstância. (...) A atitude do direito é construtiva: sua finalidade, no espírito interpretativo, é colocar o princípio acima da prática para mostrar o melhor caminho para um futuro melhor, mantendo a boa-fé com relação ao passado. É, por último, uma atitude fraterna, uma expressão de como somos unidos pela comunidade apesar de divididos por nossos projetos, interesses e convicções. Isto é, de qualquer forma, o que o direito representa para nós: para pessoas que queremos ser e para a comunidade que pretendemos ter. ${ }^{19}$

Pelo próprio pensamento esposado pelo autor chega-se à conclusão de que a teoria geral do direito é interpretativa e justificadora. E não apenas isso, mas também faz parte do próprio direito, razão pela qual deve ser usada em qualquer decisão a ser tomada. Nas palavras de Dworkin, ${ }^{20}$ (...) o voto de qualquer juiz é, em si, uma peça de filosofia de direito, mesmo quando a filosofia se acha oculta e o argumento visível é dominado por citações e listas de fatos. A doutrina é a parte geral da jurisdição, o prólogo silencioso de qualquer veredito. Finalizando essa breve exposição do pensamento de Dworkin, tem-se que o autor entende que o direito deve ser interpretado ao invés de descrito pelo texto normativo, sendo essa a maneira mais escorreita de explicar o direito.

Por essa razão que a sua teoria da integridade do direito é uma tentativa de delinear e ajustar o direito à prática jurídica, ressaltando que a interpretação da norma tem muito mais eficácia aos mecanismos judiciários que a simples descrição da lei. Não é sem razão, portanto, que Dworkin faz uma crítica ao dogmatismo do positivismo jurídico, uma vez que ele se prende à essência do texto normativo como foco principal e não à interpretação e aplicação do comando normativo às reais necessidades dos seus destinatários.

\section{A hermenêutica como ferramenta para interpretação da norma jurídica}

O grande problema que se encontra na sociedade hodierna é a questão da concretização das normas jurídicas. Na sociedade moderna, esse problema apresenta-se como um desafio a ser encarado pela práxis hermenêutica, o que deve ser feito com profundidade e dedicação. No entanto, não se pode falar de

19 DWORKIN, Ronald. M. O Império do Direito. Tradução de Jefferson Luiz Camargo. São Paulo: Martins Fontes, (1999a). p. 490.

20 DWORKIN, Ronald. M. O Império do Direito. Tradução de Jefferson Luiz Camargo. São Paulo: Martins Fontes, (1999a), p. 492. 
hermenêutica sem mencionar o filósofo e pensador Hans-Georg Gadamer. A ligação entre as ideias estabelecidas por Friedrich Müller e a hermenêutica filosófica de Gadamer é notória, sobretudo no aspecto da pré-compreensão, da necessidade de prevalência da hermenêutica ocupando uma posição dominante, em virtude de que na sociedade moderna já não se comporta mais a ideia de uma dogmática jurídica total, onde se pudesse exarar qualquer sentença por um simples ato de subsunção, como é a proposta do positivismo legalista.

Gadamer, com muita maestria, mostra a inseparabilidade entre compreender e aplicar, esclarecendo que toda aplicação é uma autêntica compreensão e, como decorrência disso, toda compreensão produz uma aplicação, e o mais importante de tudo isso é que aquele que compreende está inserido no sentido do que se compreendeu. Trazendo esse conceito para as normas jurídicas, percebe-se que o aplicar e o compreender não estão equidistantes entre si. Tome-se, por exemplo, que quando o jurista concretiza a norma aplicando-a ao caso concreto, compreende não somente a norma como passa a compreender o significado dela em sua própria existência, recebendo, então, o sentido do que foi compreendido. Esse é o verdadeiro sentido que Gadamer quis enfatizar ao estabelecer a inseparabilidade entre compreender e aplicar.

Embora não seja o objeto do presente texto fazer uma análise do pensamento de Gadamer, vale desatacar que sua hermenêutica é a filosófica, sendo seu pensamento uma contribuição extremamente valiosa para o estudo da hermenêutica e, em especial, para a Ciência Jurídica. Tal contribuição subsiste no fato de que Gadamer propõe que toda verdade é resultado direto e lógico da aplicação de um método científico. Com isso o pensador vai diametralmente oposto à ideia de que existe um método único para se alcançar a verdade. Desse modo, o pensador faz frente ao modelo tradicional de hermenêutica do século XIX. Para Gadamer, a compreensão dos fenômenos linguísticos é a bússola que dará a direção correta em busca dessa verdade almejada.

A hermenêutica filosófica de Gadamer é aquela que não se ocupa apenas com o campo epistemológico, mas também se preocupa em estudar o fenômeno da compreensão por si mesmo, razão pela qual também é conhecida como hermenêutica fenomenológica. E aqui é válido ressaltar que a preocupação do filósofo não é apenas com o fenômeno em si, mas principalmente com a operação intelectiva humana do compreender. Por isso o foco da hermenêutica filosófica não se restringe apenas aos fenômenos epistemológicos que cercam o homem, como sói acontecer com a filosofia em si, mas também na preocupação em inserir esse mesmo homem no mundo, no seu contexto social. Nas palavras do próprio Gadamer, é a existência humana como ser no mundo: 
A experiência do mundo sócio-histórico não se eleva ao nível de ciência pelo processo indutivo das ciências naturais. 0 que quer que signifique ciência aqui, e mesmo que em todo conhecimento histórico esteja incluído o emprego da experiência genérica no respectivo objetivo de pesquisa, o conhecimento histórico não aspira tomar o fenômeno concreto como caso de uma regra geral. 0 caso individual não se limita a confirmar uma legalidade, a partir da qual, em sentido prático, se poderia fazer previsões.

Seu ideal é, antes, compreender o próprio fenômeno na sua concreção singular e histórica. Por mais que a experiência geral possa operar aqui, o objetivo não é confirmar nem ampliar essas experiências gerais, para se os homens, os povos, os estados -, mas compreender como este homem, chegar ao conhecimento de uma lei - por exemplo, como se desenvolve este povo, este estado é o que veio a ser; dito genericamente, como pode acontecer que agora é assim. ${ }^{21}$

A hermenêutica filosófica, ao voltar o seu olhar para explicar o homem dentro do seu contexto, busca afastar as opiniões preestabelecidas. Com isso, ao invés de um julgamento prévio, o juiz deverá buscar, necessariamente, a compreensão do que está no texto, e o faz por meio da linguagem, através da interpretação exata do sentido da norma jurídica. Resta claro que a proposta aqui é a constante atividade do interpretar, uma vez que somente no decorrer da comunicação entre norma e intérprete é que os conceitos prévios e estereotipados vão se esmaecendo até que sejam substituídos, paulatinamente, por outros conceitos outrora desconhecidos e, por sua vez, mais adequados ao caso concreto.

É nesse contexto que a hermenêutica deve ser usada como ferramenta para a interpretação da norma jurídica, posto que se reveste de um caráter peculiar e inerente à atuação interpretativa. A palavra "hermenêutica" provém do verbo grego “hermēneuein", que, por sua vez, significa "declarar”, “anunciar", "interpretar”, "esclarecer" e que também pode ser definido por "traduzir". Em outras palavras, "hermenêutica" traduz o sentido de que alguma coisa é "tornada compreensível" ou "levada à compreensão". O termo deriva do nome do deus da mitologia grega Hermes, o mensageiro dos deuses, a quem os gregos atribuíam a origem da linguagem e da escrita e consideravam o patrono da comunicação e do entendimento humano. 0 certo é que este termo originalmente exprimia a compreensão e a exposição de uma sentença “dos deuses", a qual precisa de uma interpretação para ser apreendida corretamente.

${ }_{21}$ GADAMER, Hans-Georg. Verdade e método. Tradução de Flávio Paulo Meurer (revisão da tradução de Enio Paulo Giachini). 7. ed. Petrópolis: Vozes; Bragança Paulista: EDUSF, 2005. Coleção Pensamento Humano, p. 38. 
Portanto, pela própria definição do termo já se depreende a importância da hermenêutica como uma ferramenta indispensável à compreensão da norma jurídica, sendo essa a delimitação que se quer fazer desse termo no presente texto. Sendo a interpretação a saída para a fuga do positivismo dogmático e fechado, a hermenêutica ingressa na seara jurídica como uma poderosa ferramenta à concretização da justiça e à aplicação justa e devida do comando normativo legal, que por sua natureza pura e simples é vazio e inócuo sem a devida interpretação e aplicação à realidade e à vida da sociedade, conforme já apresentado neste texto.

Portanto, diante da complexidade das relações vividas na sociedade moderna, ou sociedade pós-positivista, o Direito tem à sua disposição essa ferramenta poderosa que é a hermenêutica, que deve ser utilizada como meio para viabilização da prestação jurisdicional, voltando-se às práticas sociais e aos demais aspectos que envolvem a sociedade como um todo, e não apenas uma análise fria e seca da lei, que por si só não proporciona nenhuma efetividade ao cidadão, consoante já observado.

O conteúdo da norma jurídica, aliado às técnicas da hermenêutica, é a instrumentalização adequada e necessária para aplicação prática do Direito nessa sociedade moderna, de tal modo que se possa pensar na tão sonhada justiça social e, como corolário disso, na pacificação social dos povos, como um dos objetivos fundamentais de todo Estado Democrático de Direito.

\section{Conclusão}

Concluindo o presente texto, tem-se que o momento ideal para uma mudança nos rumos do Poder Judiciário é agora. A mantença do atual "status quo", além de indesejável para ambas as partes (Poder Judiciário e sociedade), não resultará em nenhuma experiência frutífera e de construção social. Como foi falado no presente artigo, o foco não deve recair sobre culpado ou culpados, ou até mesmo sobre uma análise da razão pela qual chegamos a esse estágio atual, com um Poder Judiciário sucateado e sem condições mínimas de responder o cidadão à altura.

Mais que isso, o alvo deve ser uma tomada de posição no sentido de se olhar para adiante, focar o olhar no futuro, na certeza de um caminhar juntos, na expectativa de que as mudanças tão almejadas e necessárias se façam presentes mais pela prática que pela falácia. O fato é que a ideia de justiça herdada do positivismo, onde se cria lei para tentar resolver os problemas que vão surgindo na sociedade, findou por deixar uma herança de leis infindáveis, de normas inócuas, que, embora perfeitamente vigentes e bem elaboradas do ponto de vista do direito, não trazem nenhuma eficácia ao cidadão. 
A palavra do momento é exatamente a busca pela eficácia na prestação jurisdicional, é dizer, não bastar estar vigente, tem que ser eficaz, tem que atender aos anseios de justiça que vêm ecoando ao longo dos anos pelo cidadão simples, sem acesso ao Poder Judiciário, em detrimento de um dispositivo constitucional que prima pelo princípio de acesso a todos, mas que, na prática, não traz nenhuma efetividade ao cidadão, que continua sem acesso ao Poder Judiciário, seja pela ignorância legal, seja pelo exacerbado valor do processo, ou por qualquer outra causa dirimente e impeditiva a esse acesso.

É sobre essa realidade que deve ser colocado o foco de atenção no sentido de uma mudança de atitude e de direção. Os erros do passado não trarão mudanças futuras, e os mecanismos outrora utilizados também não servem de referência para essa mudança de atitude, tão necessária e urgente para a sociedade hodierna. O certo é que o simples repensar a atual realidade e o momento presente em que se vive já é um alento no sentido de mudança e, por que não dizer, a esperança de alvíssaras que se avizinham.

Sabe-se que nada nasce pronto, nada acontece acabado e completo, em especial quando se trata de normas jurídicas que compõem o ordenamento jurídico pátrio, que vão surgindo com os clamores sociais, razão pela qual vão sendo modificadas e reeditadas a cada novo momento, a cada situação específica, sendo exatamente essa a razão pela qual a Teoria Estruturante do Direito de Friedrich Müller se amolda perfeitamente ao nosso sistema judiciário, cabendo tão somente à boa vontade dos que atuam na seara do Direito o compromisso firme e sincero pela busca de mudanças.

Barreiras dos mais variados matizes geralmente são levantadas para deterem ou se oporem às mudanças, uma vez que é muito mais fácil se manter o "status quo" em nome da segurança jurídica que caminhar rumo ao novo, ao inusitado, mesmo que esse novo venha para trazer uma melhoria ao sistema como um todo. Esse cabo de guerra não trará nada de valor nem contribuirá para mudanças, sendo certo que jamais se pode tirar os olhos do alvo e se perder em elucubrações e discussões inócuas e sem nenhuma utilidade para o homem moderno, que insiste em ouvir seu clamor por justiça abafado e sem nenhuma expressão.

Que os operadores do Direito não apenas abracem as mudanças que se apresentam, mas também defendam essa bandeira com todas as forças, de tal sorte que as barreiras que porventura venham a se levantar sejam incapazes de abalar ou desviar a atenção do alvo pretendido, qual seja, a flexibilização das normas jurídicas estabelecidas no sentido de efetivar a prestação jurisdicional a todos, independentemente de classe social, cor, sexo e até mesmo idade. Uma prestação jurisdicional comprometida, de fato, com uma constituição cidadã que não apenas prolata, mas, de fato, pugna pela dignidade da pessoa humana. 
The idea of justice in the concept post-positivist and under perspective the structuring theory of law of Friedrich Müller

Abstract: The present essay seeks to a critical analysis of the idea of law that we have in today's society and the vision post-positivist from Friedrich Müller and the applicability of its structuring theory of law (Strukturiende Rechtslehre Theorie) in contemporary law. It analyzes the positivist model of applying the law as it is today, in comparison with the structural model proposed by German author, and that fits in the so-called post-positivism. In addition, it is made an approach in relation to the static model of classic positivism in counterpoint to the dynamic model of implementation of law proposed by structuring theory. Finally, with this text seeks to analyze the main characteristics of the German theory of application of the law, showing that its adoption in our law and right would, in a more concrete way, the ideal of justice for a long time sought in a globalised society and pluralistic in which we live and for this we should not forget the role of hermeneutics as a key element of this paradigm shift.

Keywords: Positivism. Post-positivism. Right contemporary. Structuring theory of law. Hermeneutics

Contents: $\mathbf{1}$ Introduction - $\mathbf{2}$ The law and its dimensions of evolution - $\mathbf{3}$ Right under the positivist view - $\mathbf{4}$ The proposal of Friedrich Müller - $\mathbf{5}$ Current legal - $\mathbf{6}$ Application of the theory structure of law in our current legal context - $\mathbf{7}$ The question of the validity and effectiveness of the rule of law $-\mathbf{8}$ The hermeneutics as a tool for interpretation of the rule of law $\mathbf{- 9}$ Conclusion - References

\section{Referências}

BARBOSA, Ruy. Oração aos moços. Marcelo Módolo (Org.). São Paulo: Hedra, 2009.

DWORKIN, Ronald. O Império do direito. São Paulo: Martins Fontes, 2007.

DWORKIN, Ronald. O Império do Direito. Tradução de Jefferson Luiz Camargo. São Paulo: Martins Fontes, 1999.

DWORKIN, Ronald. Uma questão de princípio. São Paulo: Martins Fontes, 2007.

GADAMER, Hans-Georg. Verdade e Método: traços fundamentais de uma hermenêutica filosófica. Tradução Flávio Paulo Meurer. 2. ed. Petrópolis: Vozes, 1998.

GADAMER, Hans-Georg. Verdade e método. Tradução de Flávio Paulo Meurer (revisão da tradução de Enio Paulo Giachini). 7. ed. (Coleção Pensamento Humano). Petrópolis: Vozes, 2005.

HABERMAS, Jürgen. Direito e democracia: entre facticidade e validade. 4. ed. v. 1. Tradução de Flávio Beno Siebeneichler. Rio de Janeiro: Tempo Brasileiro, 1997.

HABERMAS, Jürgen. ¿Como es posible la legitimidad por via de la legalidad? In: Revista Doxa: Cuadernos de Filosofía del Derecho, Alicante: Universidad de Alicante, n. 5, 1988.

HABERMAS, Jürgen. Teoría de la acción comunicativa. 2 v. Tradução de Manuel Jiménez Redondo. Madrid: Taurus, 1987.

HART, H. L. A. O Conceito de Direito. Tradução de A. Ribeiro Mendes. 3. ed. Lisboa: Fundação Calouste Gulbenkian, 2001.

KELSEN, Hans. O problema da justiça. 2. ed. Tradução de João Baptista Machado. São Paulo: Martins Fontes, 1996. 
KELSEN, Hans. O que é Justiça - A Justiça, o Direito e a Política no espelho da ciência. 3. ed. São Paulo: Martins Fontes, 2001.

KELSEN, Hans. Teoria geral do direito e do estado. 3. ed. Tradução de Luís Carlos Borges. São Paulo: Martins Fontes, 1998.

KELSEN, Hans. Teoria pura do direito. Tradução João Baptista Machado. 6. ed. São Paulo: Martins Fontes, 1999.

MÜLLER, Friedrich. Teoria Estruturante do Direito. 2. ed. São Paulo: Revista do Tribunais, 2009.

MÜLLER, Friedrich. O Novo Paradigma do Direito - Introdução à teoria e metódica estruturantes do direito. São Paulo: Revista dos Tribunais, 2007.

MÜLLER, Friedrich. Métodos de trabalho do Direito Constitucional. Trad. de Peter Naumann. 2. ed. São Paulo: Max Limonad, 2004.

MÜLLER, Friedrich. Interpretação e concepções atuais dos direitos do homem. Anais da XV Conferência Nacional da Ordem dos Advogados do Brasil, v. 8, mar. 2006.

SARAIVA, Paulo Lopo. Direito, política e justiça na contemporaneidade. Campinas: Edicamp, 2002.

STRECK, Lenio. Hermenêutica Jurídica $e(m)$ Crise - uma exploração hermenêutica da construção do direito. São Paulo: Livraria do Advogado, 2014.

Recebido em: 03.09.2015

Pareceres: 24.09.2015 e 21.01.2016

Aprovado em: 12.07.2016

Informação bibliográfica deste texto, conforme a NBR 6023:2002 da Associação Brasileira de Normas Técnicas (ABNT):

SILVA, Adonias Osias da; ARAúJO, Carla R. de Freitas. A ideia de justiça no conceito pós-positivista e sob a ótica da Teoria Estruturante do Direito de Friedrich Müller. Direitos Fundamentais \& Justiça, Belo Horizonte, ano 10, n. 34, p. 151-175, jan./jun. 2016. 